\title{
Comentarios morales para Juan Manuel Santos, presidente de la República de Colombia 2014-2018
}

\author{
Moral Comments for Juan Manuel Santos, President of Colombia 2014-2018
}

Carlos Eduardo Román Maldonadoํㅜ, Sociólogo, Magíster en Filosofía.

${ }^{1}$ Docente del Centro de Formación Humana, de la Corporación Universitaria Remington, Calle 51 No 51 27, Medellín, Colombia. Integrante de los coloquios de estudio y discernimiento en Humanhabil (Habilitación Humana) desde 1997. carlos.roman@uniremington.edu.co / ceromanm@antropocultura.com

(Recibido: 3 de junio de 2014; aceptado: 30 de junio de 2014)

\section{Resumen}

El artículo describe las cualidades del príncipe que Maquiavelo señala en el Príncipe, para atribuirlas al presidente Santos y entender de esta forma los valores morales del país, dado que la Presidencia de la República es una Institución con prácticas aceptadas. Las virtudes y los vicios se expresan en actos concretos que los determinan, es el carácter del individuo, su marca. Metodológicamente se tiene lo conceptual, ideas al modo de tipos puros para configurar el marco referencial de la conducta humana. Como conclusión vemos dos caminos para gobernar el país, el primero puede ser a través de la habilitación de posibilidades desde lo bueno que puede hacer por sí mismo y por la sociedad; el segundo dejar vacíos que sean llenados por las circunstancias y actitudes desesperadas de enojo e irracionalidad de los seres humanos.

Palabras clave: valores morales, vicios, virtudes.

\section{Abstract}

This paper describes the qualities of a prince, according to Machiavelli in his book The Prince, and attributes them to President Santos in order to understand the moral values of the country, since the Presidency is an institution with accepted practices. Virtues and vices are expressed in concrete acts that determine them, becoming the character of a person, his mark. Methodologically, there exist conceptual ideas -such as pure types- to set the frame of reference of human behavior. In conclusion, we foresee two ways to run the country: one committed to potentiate good actions of

${ }^{\Perp}$ Para citar este artículo: Román Maldonado CE. Comentarios morales para Juan Manuel Santos, presidente de la República de Colombia 20142018. RHS. Revista. Humanismo. Soc, Volumen 2 (1): 53-60.

\footnotetext{
* Autor para correspondencia: Carlos Eduardo Román Maldonado. Calle 60 No 75-150, Apartamento 131, Bloque 8. E-mail: carlos.roman@uniremington.edu.co; ceromanm@antropocultura.com
} 
people for their own good and that of society; the second consist in leaving gaps to be filled by human circumstances and desperate attitudes emerging from anger and irrationality.

Key words: moral values, vices, virtues.

\section{Introducción}

Comentarios morales para Juan Manuel Santos, presidente de la república de Colombia 2014-2018. Este juicio se realiza con base en la lectura del texto El Príncipe, de Nicolás Maquiavelo (1979), y en algunas obras complementarias. En concreto, nos interesa analizar las cualidades del príncipe que describe Maquiavelo y su posible atribución al presidente Santos, con el firme propósito de que coadyuven al mejor entendimiento de los valores morales del país, en tanto la Presidencia de la República sea institución moral que hace extensiva a toda Colombia valores, puesto que sus prácticas funcionan y son debidamente aceptadas. Por ello la figura del presidente debe reflejar la gloria, es decir, la "reputación, fama y honor que resulta de las buenas acciones y grandes calidades" (Diccionario de la Lengua Española, 2001, p.1139. Tomo I).

Significa que la Presidencia de la República es símbolo de la unidad nacional y expresa de alguna manera el obrar y el sentir común del colombiano. Por supuesto, no desconocemos la enseñanza de Maquiavelo sobre las pasiones y debilidades humanas. Condición cultural del ser humano que le hace afirmar a Maquiavelo que todos los hombres son dignos de alabanza o de censura, es decir, "De todo, en una palabra" (Maquiavelo, 1979, p.110). Queriendo significar la dicotomía del ser humano entre el bien y el mal, dos caminos marcan la diferencia cultural en el decir / hacer social de la historia humana, donde el hombre no es ni bueno ni malo en absoluto. No obstante, la sabiduría de la presidencia sabrá cómo obrar en determinadas circunstancias acorde al tiempo y lugar para preservar el orden y la seguridad del Estado, pues es responsabilidad suya el garantizarlas, tal como señala Maquiavelo en su obra al intuir el concepto moderno de razón de Estado.

El problema de los valores es importante porque cohesiona e integra moralmente una sociedad mediante representaciones colectivas compartidas por un grupo poblacional mayoritario de colombianos. No es un tema que se pase de soslayo, como si no tuviera nada que ver con el orden y comportamiento habitual de los colombianos, es decir, con el ethos sociocultural establecido, instituido y reconocido.

Una acotación metodológica. Para este escrito retengo solamente lo conceptual, ideas al modo de tipos puros, porque sabemos que la realidad no está prediseñada ni prefabricada et nihilo, así como tampoco es producida metaempíricamente como dada por un Dios externo que mueve los hilos de la existencia a su parecer; al contrario, enseña que la sociedad en general es un todo diferenciado compuesto por realidades multidimensionales, donde las relaciones sociales son un producto social por el hecho de generar vínculos con los demás, formas de ser social que van instituyendo significados y sentidos en el representar decir / hacer sociales. Por supuesto, no desconocemos las realidades desvinculantes producidas por los desacuerdos y conflictos que podrían generarse al garantizar la seguridad y el orden del Estado. No obstante, quiero algo positivo que atraiga realidades buenas y benéficas para el colombiano. Por ello hago eco de las palabras que Cerezo Galán (como se citó en Giraldo Zuluaga, 2007, p. 139) toma de Fichte "La clase de filosofía que se hace depende de la clase de hombre que se es". En este sentido, hay que producir situaciones que favorezcan a la humanidad, comenzando por la enseñanza de valores $\mathrm{y}$ virtudes que dignifiquen la naturaleza humana.

Un aspecto importante a destacar es que el presente escrito se gestó en el curso Relación Ética y Política, de la Maestría en Filosofía que el autor cursó, donde estudiamos, entre otros autores y textos, la obra de Nicolás Maquiavelo El Príncipe, en relación con la moral del príncipe o del héroe. 


\section{Valores morales}

“[...] en el hombre existe el germen de todas las vidas. Según la simiente que cultive, el hombre se convertirá en planta o en animal racional, o en ángel" (Reale \& Antiseri, 2004, p.82. Tomo II). Estas palabras de Pico della Mirándola podrán ser tenidas en cuenta por el presidente Santos para cultivar valores que dignifiquen al hombre y al Estado, porque de lo que siembre recogerá. Pero ¿qué simientes cultivar? Maquiavelo (1979, p.110) señala como virtudes la honestidad, la generosidad, la magnanimidad, la casticidad, la modestia, la astucia, la discreción, la blandura, y la alegría. En completa correspondencia, el diálogo entre Macduff y Malcolm, en la escena III del acto IV, nos da la respuesta con estas elocuentes palabras donde se resaltan las cualidades buenas: "[...] la justicia, la templanza, la serenidad, la concordia, la clemencia, el valor, la firmeza en los propósitos, la generosidad [...] y la miel de la concordia" (Shakespeare, sf, p.47). Significa que el presidente Santos está llamado a preservar la democracia del Estado al cultivar éstos valores y exigir en los ciudadanos virtudes equiparables para Colombia. Las instituciones del Estado con sus funcionarios deberán ser garantes y dar ejemplo con su obrar, puesto que "Por sus frutos los conoceréis" (Mt, $7,16)$. Con la enseñanza de estos valores garantizara su permanencia en el poder, la seguridad del Estado y un entorno favorable para la vida del colombiano.

No obstante, el presidente Santos podría garantizar la seguridad del Estado con virtudes contrarias si la situación así lo amerita. Maquiavelo enseña que "Un Príncipe [...] puede practicar todas las virtudes, pero muchas veces le obliga el interés de su conversación a violar las leyes de la humanidad, de la caridad y la religión. En una palabra, tan útil le es perseverar en el bien cuando no hay inconveniente, como saber desviarse de él si el interés lo exige" (1979, p.121). Algunas veces, señor presidente, podría tener presente esta dicotomía entre política y moral, donde prime la política sobre la moral. No sobra recordar que para Maquiavelo el fin justifica los medios. Aquí el fin es preservar y garantizar la seguridad del Estado con los medios coercitivos disponibles, no sea que por omitir esta consideración sobre el carácter necesario del mal se le pierda el país. Es una posibilidad siempre latente aunque no sea la más adecuada para mantener la autoridad, pero tal vez si la más efectiva por los resultados esperados.

Presidente Santos podría rechazar vicios y señalamientos de los ciudadanos de "[...] que es cruel, lascivo, hipócrita, falso, avaro, iracundo y que se junten en él todas las maldades del mundo" (Shakespeare, sf, p.46-47); así mismo que es mezquino, vicioso, duro, soberbio, alocado, melancólico, ingrato, hipócrita, inconstante e interesado (Maquiavelo, 1979, p.110, 116). Estos valores negativos son altamente dañinos para Colombia, porque asolan y confunden al país entero, tal como dice Shakespeare en Macbeth (sf, p.47. Somos nosotros quienes hacemos la extrapolación). No servirán como simiente para cultivar valores que dignifiquen al hombre y al Estado. Las instituciones del Estado deberán implementar estrategias que coadyuvan a fortalecer los valores morales que sirvan al desarrollo de la personalidad y de la ciudadanía exigiendo el cumplimiento de los deberes y las obligaciones consagradas en la Constitución Política de Colombia 1991, y en el respeto de los derechos humanos.

Por ejemplo, fortalecer la familia como centro de enseñanza moral al diferenciar lo bueno de lo malo, así con la educación y las otras instituciones necesitadas de cualidades que favorezcan el desarrollo de la ciudadanía y de la personalidad. En suma, educar al niño para no castigar al adulto, como comúnmente se dice. De no prestar la atención debida la tiranía y la anarquía aparecerán como fenómenos atípicos de la sociedad colombiana. Los vacíos que deja la atención del Estado serán llenados con realidades poco favorables y poco benéficas: la delincuencia y el vicio podrían ser unos ejemplos de ello y aparecer con violencia desmesurada. El presidente Santos está llamado a tener la suficiente inteligencia para atender y escuchar la voz del ciudadano, su clamor. El saber escuchar es pues una característica del hombre de Estado. Sería prudente y necesario en este aspecto así como en otros igual de importantes escoger "[...] hombres sabios para consejeros y permitiéndoles a ellos solos que le digan francamente la verdad sobre las cosas que les pregunte. Y debe, ciertamente, preguntarles y oír su parecer; más luego determinarse a aquello que le dicte su propia opinión [...]” (Maquiavelo, 1979, p.145), mediante el 
discernimiento recto de la razón y obrar así mismo en consecuencia.

Presidente Santos el conocimiento de las virtudes y de los vicios es necesario porque sabrá "[...] cuáles son las virtudes o los defectos que podrían perderle" (Maquiavelo, 1979, p.111) o asegurarle preservar el Estado, moverse acorde a las circunstancias políticas de tiempo y lugar. Maquiavelo enseña esta situación poniendo como ejemplo el obrar de la zorra y del león, respectivamente. Dice que "[...] debe tomar el príncipe las que distinguen al león y a la zorra y valerse de ambas. La zorra tiene poca fuerza para defenderse del lobo, y el león cae fácilmente en las trampas que se le arman, por lo cual, debe aprender el príncipe de la una a ser astuto para conocer la trampa, y del otro a ser fuerte para espantar al lobo" (1979, p.119-120). Significa que el presidente Santos se mueve en un terreno complejo confrontando intereses particulares de los individuos con los generales del Estado. El interés común es el que debe primar en lugar del particular. Para enfrentar acciones contrarias son la astucia y la fuerza que enseñan la zorra y el león. Esto no lo debe olvidar el presidente Santos si quiere el beneplácito de los ciudadanos y el bienestar común.

Claro está que sus virtudes como estadista también cuentan, no hay que dejar del todo las circunstancias políticas del manejo del Estado a la fortuna o a los casos fortuitos esperando que la suerte le sea favorable en los momentos que necesite resolver o decidir algo (Cf., Maquiavelo, 1979, p.151), puesto que para dirigir un Estado se requiere talento, y por supuesto valor, así éstas cualidades del hombre de Estado proporcionan "[...] el triunfo en sus empresas, y de las que supo su talento aprovecharse para ilustrar a su patria y engrandecerla" (Maquiavelo, 1979, p.61). Esto significa presidente Santos que las situaciones desfavorables para el desarrollo de la ciudadanía así como los obstáculos y peligros son pruebas que deberá sortear con sabiduría e inteligencia. De cómo maneje determinados acontecimientos podrá mantenerse o no en el poder. Estos hechos los puede convertir en logros políticos si sale bien librado dando solución pertinente a los problemas presentados. Al respecto, dice Maquiavelo que "Una vez allanados los obstáculos se empieza a inspirar respeto, cae desalentada la envidia, y el poder y la honra se fortalecen" (1979, p.62).
Analíticamente diferenciamos el actuar humano con conductas que podemos identificar como buenas o como malas según se las juzgue. En efecto, en el curso Relación ética y política vimos que la naturaleza humana no es abstracta, fija e inmutable, sino que la naturaleza humana es el conjunto de relaciones sociales históricamente determinadas por ciertas situaciones que hacen que se actué de cierta forma destacando cualidades que engrandecen a los hombres como de aquellas que lo rebajan. Expresado en otras palabras, es la ambivalencia humana manifestada en el decir / hacer social, donde el hombre no es ni bueno ni malo en absoluto. Las conductas concebidas como buenas son aceptadas, reconocidas e instituidas comúnmente por la mayoría de los colombianos, devienen como el pacto social que mantiene el equilibrio y la cohesión del Estado. Las malas, todo lo contrario, y son las que sentenciamos como negativas y merecen el desprecio colectivo e individual, las más dañinas son de carácter punitivo. De estas últimas el asesinato, la traición, la violación, el narcotráfico y la corrupción, reciben los más duros castigos. El ser humano tiene un sentimiento moral íntimo, es el freno para ciertas conductas que rechazamos de entrada. No las aceptamos porque corroen y corrompen el carácter.

En síntesis las obras provenientes de ambas conductas se las juzga en consecuencia, pues en política del bien puede salir el mal y viceversa (aunque sabemos que del bien no podría venir el mal pues lógicamente no es posible, pero la realidad es multidimensional y contiene también sus paradojas, irracionalidades y misterios puesto que queriendo hacer el bien resultamos haciendo el mal). Al respecto, el evangelista Mateo enseña:

\footnotetext{
Por sus frutos los conoceréis. ¿Acaso se recogen uvas de los espinos o higos de los abrojos? Así, todo árbol bueno da frutos buenos, pero el árbol malo da frutos malos. Un árbol bueno no puede producir frutos malos, ni un árbol malo producir frutos buenos. Todo árbol que no da buen fruto, es cortado y arrojado al fuego. Así que por sus frutos los conoceréis (Mt 7, 16-20).
}

Es de esperar que los valores se correspondan con las obras. Las virtudes y los vicios se expresan en la realidad en actos concretos que los determinan, es el carácter de cada individuo, su marca y huella. En efecto, el carácter es movido por la acción, por esto precisamente es el tema central de El príncipe al dedicarle todo el libro a la figura del príncipe. Dice Maquiavelo que "muchos 
han escrito ya de esta cuestión y yo lo haré también discrepando de ellos, aun cuando por ello se me considere petulante. Mi propósito es presentar las cosas como son en realidad y no como las cree el vulgo. Hay quienes ven en su imaginación repúblicas y principados como jamás existieron en la realidad. Tal es la diferencia entre el cómo se vive y el cómo se debiera vivir, [...]" (1979, p.110). Las pasiones, virtudes y vicios son de lo humano, son de su naturaleza y especie. Maquiavelo, dice Hirschberger, es uno de los que presenta "[...] al hombre tal y como él mismo se vive y se ve, al margen de otras referencias metafísicas y religiosas" (1994, p.498. Tomo I). Es pues el hombre concreto, su manifestación real en la sociedad. Para Maquiavelo el hombre no es ni bueno ni malo en absoluto "[...] pero en la práctica tiende a ser malo" (Reale \& Antiseri, 2004, p. 121. Tomo II).

Si el hombre es bueno en consecuencia y como es lógico hará actos buenos, si es malo actos malos. Claro está, es una medida relativa, porque no podemos caer en el extremo absoluto de que en el hombre no hay procesos de cambio o resiliencia, tanto para bien como para mal, la lógica lo enseña al decir A particular ad universale non valet illatio, en otras palabras, un acto particular no se puede generalizar. Pero para este escrito no nos vamos a detener en esto porque estamos mirando el marco general de los valores en la conducta humana.

Los atributos del hombre bueno tendrían más o menos estas cualidades y sus obras de seguro serian buenas. Así pues de la honestidad, el hombre honesto; de la justicia, el hombre justo; de la generosidad, el generoso; de la magnanimidad, el hombre "grande" y de buen ánimo; de la casticidad, el hombre original, auténtico, y transparente; de la serenidad, el apacible y sosegado; y así sucesivamente con las demás virtudes señaladas por Maquiavelo y Shakespeare, respectivamente.

Los atributos del hombre considerado malo serían más o menos como sigue y sus obras por supuesto no serían buenas, todo lo contrario, serían repudiadas: el cruel, será un hombre sangriento, duro, violento, le gusta hacer sufrir a los demás; el hombre lascivo, con un apetito carnal insaciable; el hipócrita, finge los sentimientos reales; el hombre falso, aquel que engaña; el avaro, el que atesora riqueza; el iracundo, el que se mantiene con rabia, con ira; y así con los demás vicios señalados por estos mismos autores párrafos arriba (claro está que para Maquiavelo también podrían ser cualidades del Príncipe).

El asunto es que van emergiendo de forma cuasi natural individuos que quieren imponer sus lógicas de acción sobre las de los otros, es como un darwinismo social donde el más fuerte es el que se adapta al entorno poniendo en riesgo y en peligro la seguridad y el orden del Estado. Así pues podemos decir que "Los hombres honrados son atropellados con frecuencia por los desaprensivos y brutales" (Hirschberger, 1994, p.502. Tomo I). Los buenos son víctimas de los malos, los pacíficos de los violentos y conflictivos, los honrados de los mentirosos. Vemos como el crimen se ha incrementado en nuestras ciudades y la impunidad es la nota sobresaliente. La crisis económica, donde surge el desempleo, el hambre, y la violación de los derechos humanos por el Estado así como por grupos armados y violentos al margen de la ley. No obstante presidente Santos este panorama desalentador y pesimista, puede superarse y trascenderse mediante:

La verdad y la justicia pueden y aún deben hacerse lo bastante fuertes para defenderse suficientemente. Condición primera para esto es que los hijos de la luz estén avisados contra las mañas y la falta de escrúpulos de los hijos de este mundo. Esto lo puede proporcionar una lectura de Maquiavelo. [...]. De este modo se robustecería el bien en el mundo y se aseguraría contra los peligros que le acechan de parte de los pillos y los desalmados (Hirschberger, 1994, p.502. Tomo I).

Presidente Santos, entonces ¿qué simiente cultivar en el colombiano? Aquellas que dignifiquen y respeten o por el contrario miseria, injustica y desigualdad. De unas y de otras vimos manifestadas en las virtudes y en los vicios señalados por Maquiavelo así como en los otros autores. Usted como jefe de Estado tiene el deber y la responsabilidad moral de dar respuesta acorde a las necesidades y realidades vividas en el presente, pero sobre todo con las del futuro, el futuro que queremos vivir, el futuro de Colombia.

PresidenteSantoshayquetener encuentalasnecesidades y realidades del presente, pero sobre todo orientar el futuro hacia adelante, donde la realidad se actualiza por las acciones de los individuos en el presente. Que no nos pase lo que a la mujer de Lot cuando ocurre la destrucción de Sodoma y Gomorra, que "su mujer miró hacia atrás y se convirtió en poste de sal" (Gn 19, 
26), significando que el mirar hacia atrás paraliza por todo lo que hay para recordar además da la sensación de que la sociedad es estática y es todo lo contrario, es movimiento, es interacción intersubjetiva mediada por actores sociales. La vida es hacia adelante, se va desenvolviendo y revelando con lo que ella tenga para mostrar. Pasó lo viejo, todo es nuevo. Vamos a lo nuevo para no convertirnos en postes de sal. Parafraseando a Maquiavelo podemos decir que situaciones nuevas son oportunas para regir nuevas leyes con el propósito de que la nación adquiera gloria porque a los hombres les preocupa más el presente que el pasado (1979, p.149). Este aspecto es importante porque las nuevas leyes se formulan acorde a las realidades del país y del entorno. Es decir, las leyes se formulan haciéndole frente a la realidad de las circunstancias, no dando la espalda a la realidad desconociendo e ignorando los problemas reales del país.

El hombre como ser humano hay que cultivarlo así como se hace con la planta al regarla con agua y abonarla para que se sostenga, así pues a un árbol le pedimos frutos. Asimismo al ser humano si lo cultivamos con justicia, educación, dignidad, empleo, posibilidades de futuro, etc., le pedimos frutos. Son éstas las semillas que debe sembrar Colombia en el ciudadano que queremos. Imaginémonos como será Colombia con personas que se hagan preguntas como esta: “ ¿Cómo dar nacimiento a aquellas ideas vitales y procreadoras, que se multiplican en miles de formas y se difunden por todos lados, haciendo avanzar la civilización y constituyendo la dignidad del hombre, [...]?" (Peirce, 1988, p.223). Esta pregunta es orientadora al respecto, porque nos muestra un panorama por explorar y va en relación con la simiente a sembrar. Una sociedad que se fije en esto con certeza dará buen fruto dignificando al hombre.

El ser humano es el que hace grande a las naciones. Los grandes personajes de la historia nos sirven como referentes y modelos a seguir para nosotros hacer lo que nos convoca en el mundo, nuestro itinerario vital creador. Esto lo mostró Maquiavelo al mencionar a emperadores romanos como Marco Aurelio, Pertinax y Alejandro. Dice de estos "[...] que son príncipes recomendables por su clemencia, por su amor a la justicia y por la sencillez de sus costumbres" (1979, p.128). Poseen valores que deben enseñarse, por ello los admiramos y recordamos, pero hasta ahí porque a cada generación le toca hacer lo suyo. Cada ser humano está en búsqueda de su realización personal y colectiva, es una constante del ser humano. Cada persona tiene un carisma y un don con el cual brillar y dar mucha gloria a la patria. Significa que las posibilidades de realización son múltiples, además de que no están predeterminadas ni diseñadas como si fueran reglas a seguir. Se dan gratuitamente y cada cual las realiza a su manera.

No se entienda como si en la sociedad no hubiera conflictos o problemas por resolver y todo fuera en cambio felicidad, como en un paraíso, todo lo contrario. Si pensáramos en una sociedad así estaríamos creyendo en las sociedades imaginadas por Platón y San Agustín, y dejaríamos de lado la gravitación de las pasiones humanas enseñadas por Maquiavelo en El Príncipe.

En realidad, lo que se espera es que el Estado garantice los derechos a que sean acreedores los colombianos en la Constitución Política de Colombia 1991. Necesitamos una sociedad justa, equitativa, solidaria, donde el ciudadano sienta y vea resultados del Estado frente a la solución de problemas del país, no promesas y más promesas realizadas por sus dirigentes con proyectos desgraciadamente no logrables porque se quedan en el papel y no se ejecutan por la corrupción, para lo cual es indispensable que el Estado corrija al legislar y obligue a los sujetos a pagar los delitos acorde con el daño causado. Necesitamos una sociedad donde las personas puedan desarrollar su proyecto de vida, esto es proyectarse en el espacio y en el tiempo en la realización de actividades que permitan la plena realización humana y su vocación de servicio. Una sociedad justa y decente, en la que el ciudadano crea en sus instituciones, las valore y respete.

\section{A modo de conclusión}

Las cualidades del ciudadano van en relación con los actos realizados, con las obras humanas. Si en los ciudadanos se siembran valores que dignifiquen al ser humano de seguro sus obras serán pertinentes y grandes. Hay mucho talento. Lo que hay que hacer es cultivar al ciudadano en las posibilidades que da la vida y la realidad para que crea y realice grandes obras para el país y el mundo. En últimas hay que creer en que se pueden hacer acciones favorables para el desempeño humano. En un país como el nuestro necesitamos 
es creer que se puede, así pues no es necesario ir al extranjero a realizar nuestros anhelos y deseos de realización personal y profesional.

El Estado debe estar a la altura de sus ciudadanos y de su tierra, razón por lo cual debe posibilitar estructuras de oportunidad favorables para que las personas logren hacer en este mundo lo que la naturaleza humana y social indiquen para bien. Hay que construir el territorio con el propósito de lograr la tranquilidad, dado que la tranquilidad es la mejor forma de vida que se pueda tener.

En este escrito se muestran dos caminos para gobernar y conducir el país al analizar las virtudes y pasiones humanas sobre todo desde Maquiavelo. Vimos que el hombre en absoluto no es ni bueno ni malo, pero el carácter del hombre es formado acorde a lo que recibe del entorno y a lo que forja en su personalidad. No se puede caer en el extremo de lo demasiado humano, porque las pasiones se contraponen a las virtudes. Esto lo enseña Maquiavelo de forma descarnada y cruda, al decir que el hombre es ingrato, hipócrita, inconstante e interesado (1979, p. 116). No obstante, Maquiavelo dice al final del libro, cuando exhorta a liberar a Italia de los extranjeros, que las situaciones se pueden revertir, al emprender acciones novedosas. Con esta idea da a entender que no hay nada fijo ni inmutable, que no se pueda cambiar por otro estado de cosas, así pues esas pasiones que caracterizan de forma cruda al hombre se pueden cambiar por virtudes que lo glorifiquen. "Lo que más favorece a un príncipe nuevo son las innovaciones que establece. Hay muchas cosas que reformar en Italia y existen manos que pueden hacerlo, pero faltan cabezas" (1979, p.157).

En nuestra contemporaneidad hacemos eco de las palabras de Maquiavelo al decir sobre los dos caminos mencionados al presidente Santos: el primero puede ser a través de la habilitación de posibilidades en el ser humano desde lo bueno que puede hacer por sí mismo y por la sociedad; y el segundo dejar vacíos que sean llenados por las circunstancias y actitudes desesperadas de enojo e irracionalidad de los seres humanos dando vía a una desesperanza aprendida.

Si elige el primero habrá de implementar estrategias con cursos de acción definidos que fortalezcan las instituciones sociales del Estado con programas de intervención acordes a las realidades específicas de cada situación. La familia como institución básica de la sociedad podrá apoyar en la formación moral así como las instituciones de educación, pero el Estado debe ser garante y dar ejemplo con su actuar. Debe hacer presencia con programas donde los individuos se sientan respaldados por un Estado justo y decente que responda por los intereses colectivos de los ciudadanos sin dejar de lado las iniciativas particulares.

Si elige el segundo camino habrá de fortalecer la justicia y las fuerzas del Estado para contrarrestar el influjo de actividades dañinas y costosas en términos de integración social y moral. Es más costoso en términos de recursos humanos y económicos, por cuanto habrá que aumentar la burocracia al darle apertura a nuevos programas que resuelvan o minimicen tales situaciones. No será el camino más favorable ni el más adecuado para el desarrollo de un Estado.

En una nación el ser humano es el centro, no las racionalidades técnicas de la economía y de la administración burocrática que reducen el ser humano a su expresión funcional, que de un fin en sí mismo pasa a ser un medio para la realización de actividades en el mundo. 


\section{Referencias}

Biblia de Jerusalén. (1998). Bilbao: Desclée de Brouwer.

Constitución Política de Colombia 1991. Bogotá: ECOE.

Giraldo Zuluaga, C. (2007). Capítulo 3. Los rasgos metafísicos del hombre. En: --------. La incógnita insoportable. El sentido del hombre en Pedro Laín Entralgo. (p.139-215). Medellín: Universidad Pontificia Bolivariana.

Hirschberger, J. (1994). Historia de la Filosofía. Antigüedad, Edad Media, Renacimiento. 15 ed. Barcelona: Herder. Tomo I.

Maquiavelo, N. (1979). El príncipe. Cali: Andreus.
Peirce, C. S. (1988). El hombre. Un signo. El pragmatismo de Peirce. Barcelona: Crítica.

Real Academia Española. (2001). Diccionario de la Lengua Española. Vigésima segunda edición. Madrid: Espasa Calpe. Tomo I.

Reale, G. \& Antiseri, D. (2004). Historia del pensamiento filosófico y científico. Del humanismo a Kant. 4 edición, 1 reimpresión. Barcelona: Herder. Tomo II.

Shakespeare, W. (sf). Macbeth. Progreso. 